\title{
Technogenic sand as activator of cement hardening
}

\author{
Marina Sergeevna Ageeva \\ Department of construction material science, objects and \\ structures \\ Belgorod State Technological University named after \\ V.G. Shoukhov \\ BSTU named after V.G. Shoukhov \\ Belgorod, Russia \\ 308012, Kostukov St., 46 \\ ageevams@yandex.ru
}

\author{
Alexey Nikolaevich Botsman \\ Department of construction material science, objects and \\ structures \\ Belgorod State Technological University named after \\ V.G. Shoukhov \\ BSTU named after V.G. Shoukhov \\ Belgorod, Russia \\ 308012, Kostukov St., 46
}

\author{
Larisa Nikolaevna Botsman \\ Department of material science and material technology \\ Belgorod State Technological University named after \\ V.G. Shoukhov \\ BSTU named after V.G. Shoukhov \\ Belgorod, Russia \\ 308012, Kostukov St., 46 \\ lora80@list.ru
}

\author{
Alina Valentinovna Ishchenko \\ Department of material science and material technology \\ Belgorod State Technological University named after \\ V.G. Shoukhov \\ BSTU named after V.G. Shoukhov \\ Belgorod, Russia \\ 308012, Kostukov St., 46
}

\author{
Anna Nikolaevna Krivenkova \\ Department of construction material science, objects and structures \\ Belgorod State Technological University named after \\ V.G. Shoukhov \\ BSTU named after V.G. Shoukhov \\ Belgorod, Russia \\ 308012, Kostukov St., 46 \\ anit-ka@mail.ru
}

\begin{abstract}
One of the possible fields of application of wet magnetic separation waste of ferruginous quartzite was considered in the paper. For Belgorod and neighbouring regions, the problem of this waste utilization is quite acute. The most effective specific surface of the filler, by which the averaging of grains with insignificant inclusion of larger aggregates is observed, was revealed. At that, large particles of technogenic sand, presented mainly by contact metamorphic quartz, facilitate the grinding intensification, acting as peculiar additional grinding bodies, but the grains themselves in waste magnetic separation (WMS) acquire a rounded cubical form, increasing packing density of the mixture. The use of finely ground microadmixture in cement showed that introduction of $1 \%$ of the waste mass of wet magnetic separation of ferruginous quartzites with the specific surface of $600 \mathrm{~m}^{2} / \mathrm{kg}$ increases the cement strength approximately 1,7 times.

Keywords-active mineral admixtures, waste of wet magnetic separtion of ferruginous quartzites, cement hardening
\end{abstract}

\section{INTRODUCTION}

Interest in the problem of using finely ground and superdispersed materials in the technology of astringents and concretes increases every year. At that, the most important question of this direction of studies is a mechanism of influence of admixtures on the hydration processes of the mixed astringent and formation of the stone structure [1-3]. Understanding the physical and chemical essence of occurring processes allows controlling them, and, consequently, synthesizing materials with a specified set of exploitation characteristics [4-6].

The structure exerts a decisive influence on the strength and deformable characteristics of concrete. It is coarsely heterogeneous and is formed as a space lattice made of cement stone, which is filled with grains of coarse and fine fillers and is penetrated with numerous defects in the form of microcracks, micropores and capillaries, containing chemically inbound water, water vapours and air.

The structure of cement stone is complex and heterogeneous. Interaction of the hard crystal part of cement stone with its lamella gel part exerts a decisive influence on the concrete strength. The gel constituent decreases with time whereas crystal one increases. The nature of nucleation and crystallisation of a new phase during hardening of the astringent materials is determined by the values of the interface area, specific surface of the material. The ratio in time between two constituents of cement stone mainly depends on the cement grade and fineness of grinding. The 
finer the cement grinding is, the quicker the hard crystal part grows [7].

The latter is also explained by the fact that the concentration of defects on the surface of cement particles grows exponentially with a decrease of the crystal size. Therefore, high rates of hydration of fine fractions of cement are connected not only with their high specific surface, but also with their higher defect concentration on the surface.

Hence, it is evident that the most important characteristic of the astringent is a value of the area of specific surface, connected with the granulometric composition. Therefore, it is necessary not only to increase the specific surface of astringents, but also to try to provide an optimal granulometric composition by means of introduction of different fillers $[8,9]$. The nature and properties of the filler exert considerable influence on the quality of the astringent.

It is known that when introducing mineral aggregates and fillers in cement systems, the processes of hydration of clinker minerals are intensified. When hydrating Portland cement in the presence of minerals-admixtures, the displacement to earlier terms of beginning of hydrate masses' formation is observed. The intensity of the processes of hydrates accumulation increases [10].

The effective influence of finely dispersed admixtures in cement is based on a property of their particles to act as nucleation centres, i.e. to accelerate the initial stage of chemical hardening [11].

The accumulated scientific and practical experience of utilization of industrial waste in Russia and abroad allows assessing it as a valuable raw material for production of building materials. A complex, physical and chemical composition and structure of waste of a number of industrial productions allow considering them as a real raw-material base of the building materials industry, including production of astringents.

For the Central Black Earth Region of RF, the problem of effective use of waste of mining and beneficiating productions is quite acute. It is known that a large number of works are devoted to an opportunity of applying the rocks and technogenic KMA waste in construction.

Extraction of ferruginous quartzites is accompanied by emission of large amount of waste of wet magnetic separation (WMS). Technology of their storage in the surface tailing dumps includes transporting, piling, payment for seized grounds, pumping the water for recirculated water supply, providing safe exploitation of hydro-engineering facilities, etc., which leads to considerable expenditures, increasing the cost price of iron-ore concentrates and reducing production profitability $[12,13]$.

Therefore, it is economically feasible to use technogenic KMA waste as a fine-grained aggregate and filler of astringents. On the territory of Kursk magnetic anomaly, the large-tonnage waste is the waste of wet magnetic separation (WMS) of ferruginous quartzite (Fig. 1).

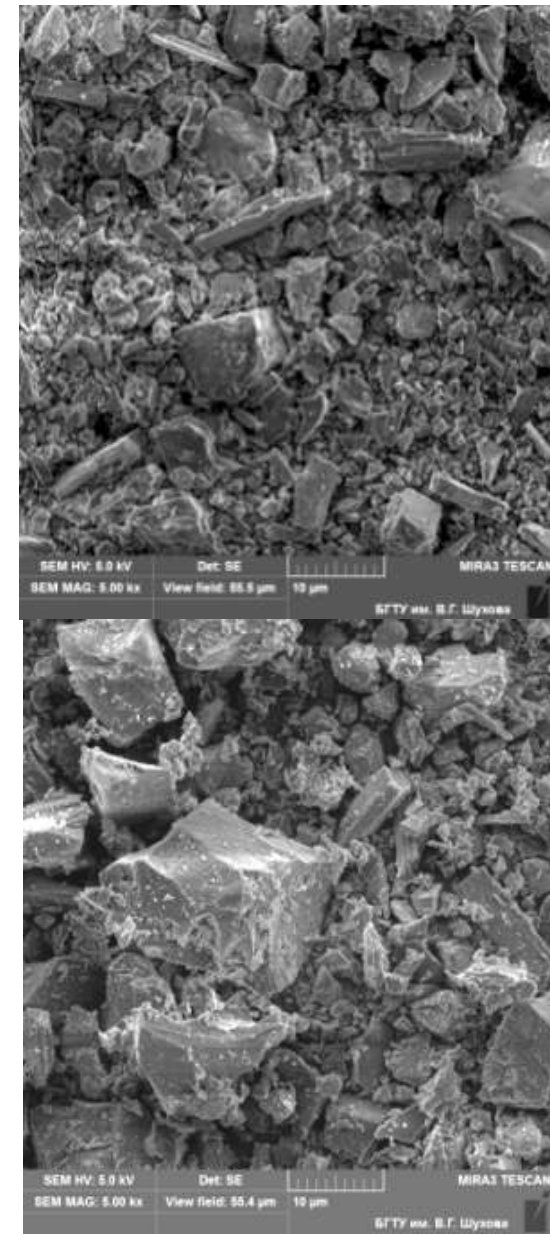

Fig. 1. External view of WMS waste of ferruginous quartzites

Besides, these are primary components which have accumulated energy as a result of geological and technogenic effects. The energy, accumulated in the tailings under the influence of the mechanical activation, affects the processes of structure formation in the system "wet magnetic separation waste of ferruginous quartzites Portland cement". Thus, for example, during refinement of polymineral rocks (granite, gneiss, diorite, etc.) during destruction by the contacts of minerals, grains of primary minerals preserve the form similar to habitus of their crystals (prismatic, columnar, needle-shaped, lamellar, isometric, etc.) $[14,15]$. When monomineral rock (quartzite, limestone) is destructed, the grain form is determined by structural and texture peculiarities (presence or absence of grain orientation in space), mineral composition (crystal habitus, type of cleavage), typomorphic peculiarities (degree of defectiveness of mineral aggregates, etc.). This determines the peculiarities of the synthesis of new formations when interacting with cement [16].

The use of wet magnetic separation waste as a mineral admixture is more effective as compared to quartz sand of sedimentary rocks. This is conditioned by typomorphic peculiarities of raw materials, defectiveness of its crystal lattice, presence of gas admixtures, fluids and mineral- 
forming environment, i.e. they are genetically active raw material [17].

In this paper, cement samples with different contents of the mineral admixture, represented by WMS waste of ferruginous quartzites, were studied. To obtain samples, the following materials were used: WMS waste, ground up to the specific surface of $400 \mathrm{~m}^{2} / \mathrm{kg}$ and $600 \mathrm{~m}^{2} / \mathrm{kg}$; Portland cement TSEM I 42.5N GOST 31108-2003. The influence of different WMS dosages on the strength of the sample sized $1 \times 1 \times 1 \mathrm{~cm}$ was studied.

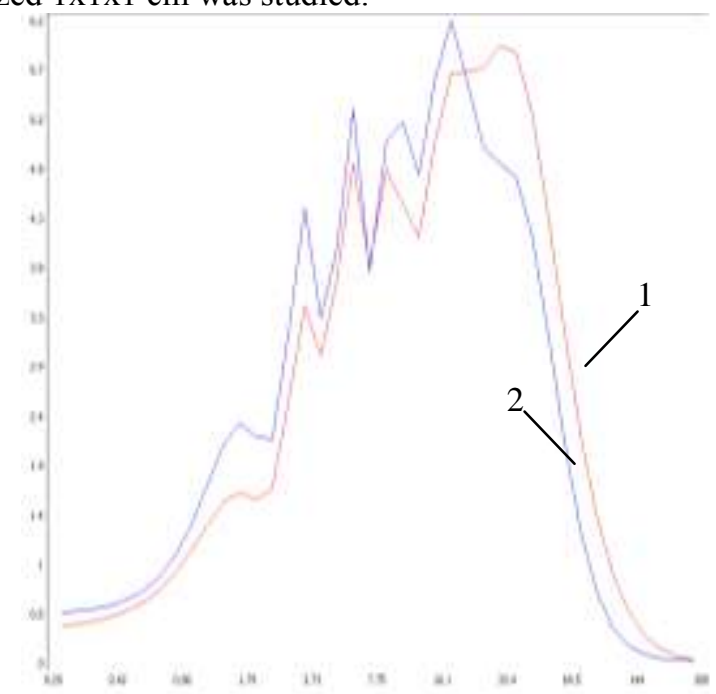

Fig. 2. Results of particle-size distribution, obtained on the laser analyser of particles "Microsizer" 201:1- $400 \mathrm{~m}^{2} / \mathrm{kg}, 2-600 \mathrm{~m}^{2} / \mathrm{kg}$.

The study of the granulometric composition, which exerts influence on water consumption, rates of strength accumulation, activity of astringents allows one to broaden the idea about materials, "looking inside" the fine-dispersed systems. The granulometric composition of the filler, ground up to different specific surfaces, was studied (Fig. 2, Tables 1,2).

TABLE I. CORRESPONDENCE BETWEEN THE PARTICLE SIZE $(\mathrm{D}, \mu \mathrm{M})$ AND THE SPECIFIED VALUES OF THE WEIGHT FRACTION.

\begin{tabular}{|c|c|c|}
\hline $\mathrm{D}, \mu \mathrm{m}$ & $400 \mathrm{~m}^{2} / \mathrm{kg}$ & $600 \mathrm{~m}^{2} / \mathrm{kg}$ \\
\hline 2 & 10.8 & 14 \\
\hline 3 & 15.1 & 19.5 \\
\hline 4 & 20.3 & 26 \\
\hline 5 & 24.1 & 30.1 \\
\hline 6 & 28.7 & 35.2 \\
\hline 10 & 41 & 48.2 \\
\hline 40 & 81.6 & 87.9 \\
\hline 150 & 99.6 & 100 \\
\hline 200 & 100 & 100 \\
\hline 300 & 100 & 100 \\
\hline
\end{tabular}

TABLE II. WEIGHT FRACTION OF PARTICLES (P, \%), CORRESPONDING TO SPECIFIED VALUES OF PARTICLE SIZES

\begin{tabular}{|c|c|c|}
\hline $\mathrm{P}, \%$ & $400 \mathrm{~m}^{2} / \mathrm{kg}$ & $600 \mathrm{~m}^{2} / \mathrm{kg}$ \\
\hline 10 & 1.82 & 1.45 \\
\hline 20 & 3.93 & 3.08 \\
\hline 30 & 6.3 & 4.97 \\
\hline 40 & 9.59 & 7.36 \\
\hline 50 & 14.6 & 10.6 \\
\hline 60 & 20.3 & 15.3 \\
\hline 70 & 27.9 & 20.7 \\
\hline 80 & 38 & 29.5 \\
\hline 90 & 54.3 & 43.8 \\
\hline 100 & 300 & 300 \\
\hline
\end{tabular}

When comparing the granulometric composition of two fillers, the following results were obtained. Thus, the most number of particles in both cements corresponds to the sizes of $2-100 \mu \mathrm{m}$. WMS 600 differs from WMS 600 by the displacement in the interval of sizes $100-150 \mu \mathrm{m}$ in the direction of greater values. This predetermines a higher water demand in the latter. The presence of a greater number of ultimate particles, beginning with $40 \mu \mathrm{m}$ in WMS 600, allows implying a higher reactivity of the filler. It is evident that a water consumption increase of the filler can lead to the increase of the water consumption of the cement system on its basis. This must be taken into account when selecting an optimal amount of admixture.

The stick-slip nature of the curve of the granulometric composition exerts a positive influence on the formation of the microstructure of cement stone owing to a denser spatial piling of particles and, consequently, obtainment of denser stone. WMS 600 waste has a displaced location of particles by sizes in the direction of low values, which predetermines higher rates of astringent hydration using this admixture.

Hydraulic activity of materials, widely used as finely ground mineral admixtures in astringents (natural and technogenic sands, slags, volcanic rocks, etc.), was studied in numerous works of the Russian and foreign experts. The peculiarities of manifesting pozzolatic and hydraulic properties by such materials is of great importance from the viewpoint of their application in the composition of composite astringents and their influence on cements' durability.

The pozzolatic reaction is distinctive because the mixture of pozzolan, calcium hydroxide and water consolidates already at room temperature. Although pozzolans, as such, are absent from natural and technogenic sands with a high dispersity degree, obtained by mechanic and chemical activation, mineral crystal material transforms into amorphous. As a result, owing to obtained reserve of free energy and thermodynamic instability, amorphized particles of non-clinker components can manifest hydraulic 
activity. The products of interaction of natural and technogenic sands with calcium hydroxide, as is known, are mainly low-base hydrosilicates C-S-H (I), hydroaluminates and calcium hydroferrites, which improves strength and deformability properties of concrete, increasing the gel constituent of cement stone $[7,8]$.

It is established that introduction of waste in all cases increases the strength of samples as compared to the test cement (Table 3, $\Delta \mathrm{R} 28, \%$ ).

Pozzolatic effect of influence of finely dispersed admixtures in concretes manifests itself in the chemical interaction of active silica with lime by the scheme:

$$
\mathrm{SiO}_{2}+\mathrm{Ca}(\mathrm{OH})_{2}+\mathrm{n}\left(\mathrm{H}_{2} \mathrm{O}\right)->(\mathrm{B}) \mathrm{CaO} \mathrm{SiO}_{2} \mathrm{H}_{2} \mathrm{O}
$$

At that, the strengths of samples, containing the admixture with the specific surface of $600 \mathrm{~m}^{2} / \mathrm{kg}$, with different dosages of the latter, are close in values between themselves, which reduce gradually with the increase of the WMS dosage. Thus, with $1 \%$ of consumption, this indicator is higher approximately by $16 \%$ as compared to samples with a $15 \%$ dosage (Table 3 , Fig. 3 ). This is related to the specific surface of WMS waste and, as a consequence, to the increase of water consumption along with the admixture consumption.

TABLE III. CHARACTERISTICS OF OBTAINED SAMPLES.

\begin{tabular}{|c|c|c|c|c|c|c|}
\hline \multirow[t]{2}{*}{ Type of sample } & \multirow{2}{*}{$\begin{array}{c}\text { WMS specific } \\
\text { surface, } \\
m^{2} / k g\end{array}$} & \multirow{2}{*}{$\begin{array}{c}\text { Density, } \\
\mathrm{kg} / \mathrm{m}^{3}\end{array}$} & \multicolumn{3}{|c|}{$\begin{array}{c}R, \\
M P a\end{array}$} & \multirow[t]{2}{*}{$\begin{array}{c}\Delta R 28, \\
\%\end{array}$} \\
\hline & & & $\begin{array}{c}3 \\
\text { days }\end{array}$ & $\begin{array}{c}7 \\
\text { days }\end{array}$ & $\begin{array}{c}28 \\
\text { days }\end{array}$ & \\
\hline Cement (c) & & 2045 & 5.8 & 21 & 32 & 0 \\
\hline $\mathrm{C}+$ muroplast & & 2110 & 6.2 & 22 & 33 & 3 \\
\hline $\mathrm{C}+\mathrm{WMS}(1 \%)$ & \multirow{4}{*}{400} & 2101 & 5.7 & 25 & 37 & 15.6 \\
\hline $\mathrm{C}+\mathrm{WMS}(5 \%)$ & & 2120 & 5.1 & 24 & 36 & 12.5 \\
\hline$c+$ WMS $(10 \%)$ & & 2080 & 5.6 & 31 & 43 & 34 \\
\hline $\mathrm{c}+\mathrm{WMS}(15 \%)$ & & 2110 & 5.7 & 15 & 32 & 0 \\
\hline $\mathrm{c}+\mathrm{WMS}(1 \%)$ & \multirow{4}{*}{600} & 2200 & 9 & 34 & 50 & 56 \\
\hline $\mathrm{c}+\mathrm{WMS}(5 \%)$ & & 2027 & 5.4 & 29 & 42 & 31 \\
\hline $\mathrm{c}+\mathrm{WMS}(10 \%)$ & & 2337 & 4.5 & 26 & 38 & 15.6 \\
\hline$c+$ WMS $(15 \%)$ & & 2115 & 4.9 & 27 & 37 & 18.8 \\
\hline
\end{tabular}

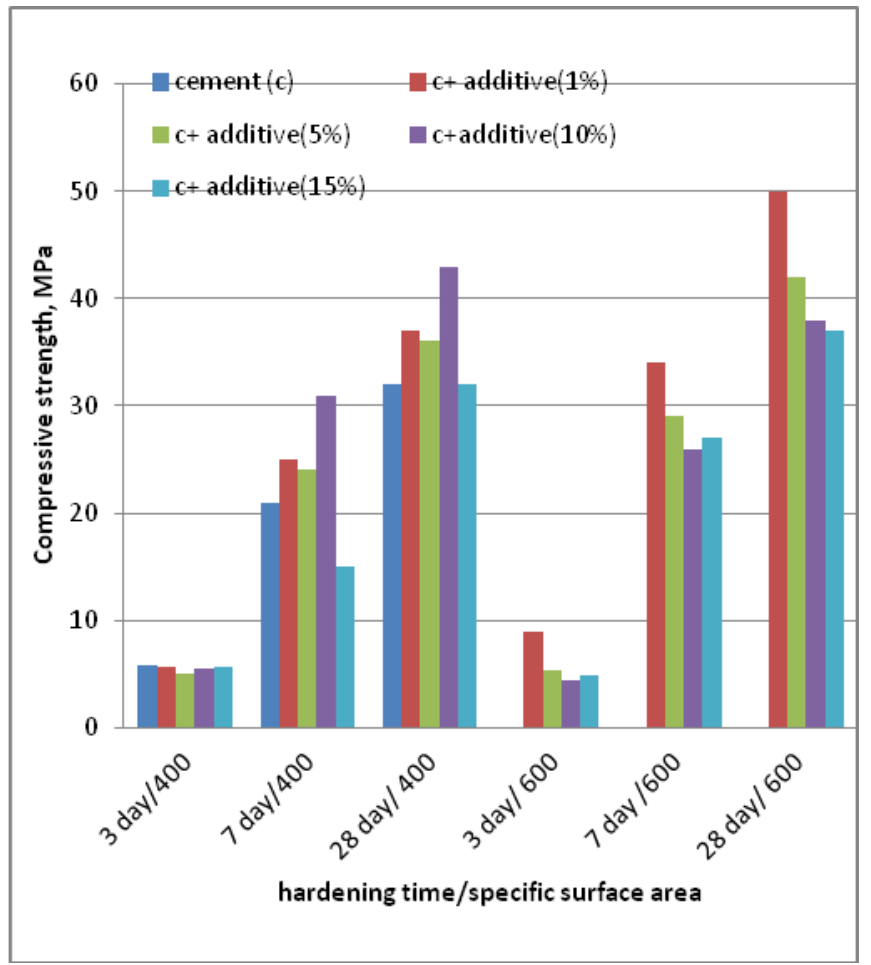

Fig. 3. Strength of cement samples with admixture of WMS waste of ferruginous quartzites

Introduction of WMS waste with the specific surface of $400 \mathrm{~m}^{2} / \mathrm{kg}$ has a similar effect. Maximum surge in strength is observed in samples with $1 \%$ of admixture content. Strength of these compositions is higher as compared to that of cement by $56 \%$. The dosage from 1 to $5 \%$ of WMS produced similar results by the strength of 36-37 MPa, and with a $15 \%$ consumption, the strength of samples reduced to the similar indicator of cement.

Chemical and mineralogical characteristics of admixture and pozzolatic influence on the basic properties of the astringent system in the early period do not exert considerable influence since new phases-crystalline hydrates occupy an insignificant volume.

But at the second stage of hydration, chemical processes in the mixed astringents take on a great importance and lead to substantial change of the phase composition of the system: the balance between primary crystalline hydrates (portlandit and high-base calcium hydrosilicates - CHS) and secondary more stable fine-crystalline hydrates (low-base CHS) shifts in the direction of the latter. Displacement of the balance depends, in the first place, on the chemical and mineralogical factors - the chemical composition and pozzolatic activity of admixtures. Balance displacement of hydrated new formations in the direction of the increase of the number of low-base CHS of C-S-H(1)-type is a necessary condition of increasing the density and strength of cement stone. 
However, this condition is sufficient until excessive amount of filler is enveloping the surface of new phases and by this preventing from formation contacts of intergrowth between crystalline hydrates. Thus, in the mixed system, there is an optimal volume concentration of finely dispersed material with consideration of its hydraulic activity. For inert micro-filler, an optimal dosage can be a volume comparable with the volume of capillary pores and necessary for consolidation of the structure.

The samples structure of the optimal compositions is homogeneous with uniformly distributed microformations throughout the entire volume of the material. However, microporosity, related to the increase of water consumption of samples when introducing $15 \%$ of WMS, is observed in samples with a high consumption of admixture (Fig. 4).

At that, a denser packing of grains owing to a decrease of filler's particle sizes and an increase of their number is observed. This is related to the destruction of not only aggregates of minerals, but also partially of rock forming minerals.

Coarse particles - grains of clinker and separate clinker minerals, active mineral admixtures, hydrated from the surface, become the sites of the space lattice of cement stone.

Crystalline hydrates, formed simultaneously or subsequently depending on the activity of the initial mineral, fill free space in the cement stone and bind with already existing frame. Strength of the consolidated system will be determined by the strength of the crystals themselves. Therefore, the higher the strength of the admixture particles introduced in the cement is, the better the whole system strengthens.

By the nature of particles and their coarseness, it is possible to imply that a chalcedonic variant of the regionally metamorphized weakly ordered quartz will be ground faster, then - dynamometamorphic, and after it - contactmetamorphic quartz will be ground.

Thus, the authors proposed the principles of increasing the effectiveness of the cement systems, consisting in using a finely ground mineral component, WMS waste of ferruginous quartzites, obtained by the grinding up to the optimal specific surface, which owing to the complex synergetically strengthened influence of the filler, as well as the heterogeneous granulometric composition, will exert directional influence on the formation of the structure during consolidation of the astringent, densening and strengthening the structure.

The most effective specific surface of the filler, by which grains' averaging is observed in case of insignificant embedment of coarser aggregates, was revealed. At that, coarse particles of technogenic sand, mainly represented by contact metamorphic quartz, enable intensification of grinding, acting as peculiar additional grinding bodies,
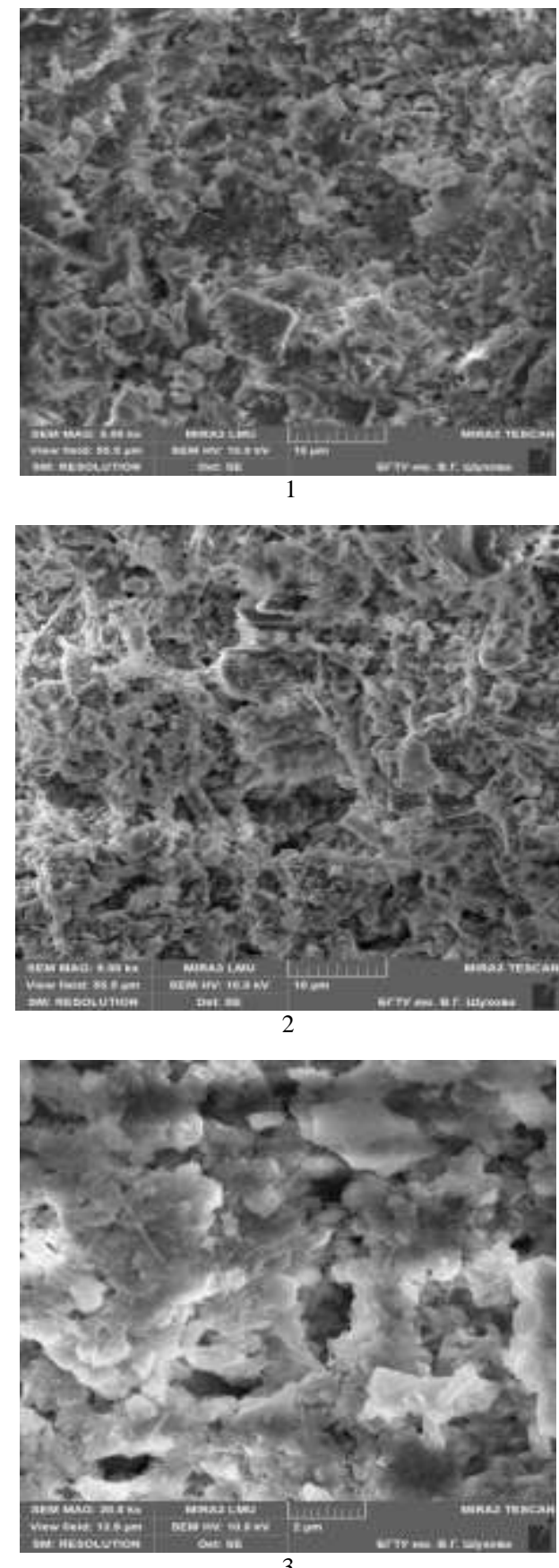

3

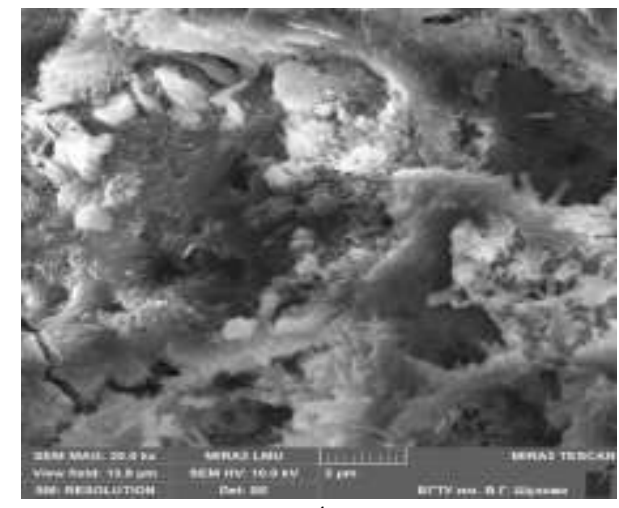

4

Fig. 4. Microstructure of cement samples with WMS admixture: 1,2-x5000; 3,4-x20000. 
whereas the WMS grains themselves acquire rounded cubical form, increasing the density of mixture packing.

It was established that the optimal dosage of WMS waste with specific surface of $600 \mathrm{~m}^{2} / \mathrm{kg}$ is $1 \%$ of the cement mass. This is related to the high specific surface of WMS waste and, as a consequence, to the increase of water consumption along with the increase of admixture consumption. With the specific surface of $400 \mathrm{~m}^{2} / \mathrm{kg}$, the maximal strength is reached with a $10 \%$ consumption of the admixture.

Using $1 \%$ by the mass of finely ground WMS as a microadmixture to cement with the specific surface of 600 $\mathrm{m}^{2} / \mathrm{kg}$ led to the 1,7-time increase of the cement strength. This will allow decreasing the cement consumption or using cement of the lower grade. This is especially relevant under conditions of economic crisis and price rising during construction.

\section{Acknowledgment}

This work is realized under financial support of the Ministry of Education and Science of the Russian Federation, Federal Action Program «Research and Development in Priority Fields of Science and Technology of Russian Federation for 2014-2020», unique agreement identifier RFMEFI58317X0063, using equipment of the High Technology Center at BSTU named after V.G. Shoukhov.

\section{References}

[1] L.A. Suleymanova, V.S. Lesovik, K.A. Kara, M.V. Malyukova, K.A Suleymanov, "Energy-efficient concretes for green construction", Research Journal of Applied Sciences, V. 9, № 12, pp. 1087-1090, 2014

[2] I.L. Chulkov, E.V. Fomina, A.V. Cherevatova, E.V. Voitovich, "Increase of effectiveness of cement astringents with active mineral nanodispersed component," Herald of Siberian State Automobile and Highway Academy, 5, 2015, pp. 56-62.

[3] N.I. Kozhukhova, R.V. Chizhov, I.V. Zhernovsky, V.V. Strokova, "Structure formation of geopolymer perlite binder vs. type of alkali activating agent", ARPN Journal of Engineering and Applied Sciences, vol 20 (11), pp. 12275-12281, 2016.

[4] R.V. Lesovik, Fine-grained concrete on composite knitting and industrial sands, thesis for the degree of Doctor of Technical
Sciences, Belgorod State Technological University named after V.G. Shukhov, 2009.

[5] M.S. Ageeva, R.V. Lesovik, V.T. Erofeev, D.M. Sopin, G.A Lesovik, The efficient composite building materials of the iron and steel industry waste*, 19-te INTERNATIONALE BAUSTOFFTAGUNG IBAUSIL, 2015, pp. 1433-1435.

[6] M.S. Ageeva, G.A. Lesovik, D.M. Sopin, Filling mixturews based on technogenic raw material (monography). Belgorod: Publisher BSTU named after V.G. Shukhov 2014, p.160.

[7] R.V. Chizhov, N.I. Kozhukhova, I.V. Zhernovsky, D.N. Korotkikh, E.V. Fomina, M.I.Kozhukhova, "Phase formation and properties of aluminosilicate binders of nonhydrating type of hardening using perlite”, Construction Materials, №3, pp. 34-36, 2015

[8] V.V. Strokova, L.N. Botsman, Y.N. Ogurtsova, "Impact of Epicrystallization Modifying on Characteristics of Cement Rock and Concrete", International Journal of Applied Engineering Research, Vol. 10 (24), pp. 45515-45521, 2015.

[9] M. Yu. Elistratkin, E.A. Pospelova, D.D. Netsvet, "Statistical Analysis as an Instrument for Improving the Quality of Products from Cellular Concrete," Applied Mechanics and Materials, Vols. 670-671, pp. 1624-1628, 2014

[10] V.S. Lesovik, N.I. Alfimova, P.V. Trunov, "Reduction of energy consumption in manufacturing fine ground cement," Research Journal of Applied Sciences, Vol. 9(11), pp 745-748, 2014.

[11] R.V. Lesovik, A.N.Nosova, A.V. Savin, E.V. Fomina, “Assessmen of the Suitability of the Opal-Cristoballite Rocks of Korkinsk Deposit in the Construction Industry," World Applied Sciences Journal, vol 29 (12), pp. 1600-1604, 2014.

[12] S.V. Sverguzova G. I. Tarasova, I.V. Starostina, E.V. Fomina, "Using Ferruginous Quartzite Tailings in Dry Building Mixes," International Journal of Applied Engineering Research (IJAER), 10(24), pp. 45082-45090, 2015.

[13] V.V. Nelubova, V.V. Strokova, A.V. Sumin, I.V. Zhernovsky, "The structure formation of the cement stone with nanostructured modifier", Key Engineering Materials, Vol. 729, pp. 99-103, 2017.

[14] E.V. Fomina, V.V. Strokova, N.I. Kozhukhova, A.E. Fomin, "Effect of mechano activation on size parameter of aluminosilicate rocks", Indian Journal of Science and Technology, vol. 9(22), pp. 95545, 2016.

[15] E.V. Fomina, N.P. Kudeyarova, V.V. Tyukavkin, "Activation of hydration of composite astringent based on technogenic raw material", Construction materials, 12, pp. 61-64, 2015.

[16] R.V. Lesovik, Fine-grained concretes on composite astringents and technogenic sands, Dissertation for a degree of Doctor of Engineering, Belgorod State Technological University, 2009, Belgorod.

[17] N.I. Kozhuhova, I.V. Zhernovskiy, M.S. Osadchaya, V.V. Strokova, R.V. Tchizhov, "Revisiting a selection of natural and technogenic raw materials for geopolymer binders", International Journal of Applied Engineering Research, vol 9 (22), pp. 16945-16955, 2014. 